\title{
Insight into interplay of some molecular chaperones in a hill stream teleost, Barilius bendelisis under wide seasonal and diurnal thermal fluctuations
}

\author{
Saurabh Dewan*, Yashpal Singh, JP Bhatt \\ Proteomics Cell, Fish Pheromone and Behavior study Unit, UGC-SAP Department of Zoology \& Biotechnology, HNB Garhwal University, Uttarakhand, \\ India.
}

\section{ARTICLE INFO \\ Article history: \\ Received on: 19/11/2015 \\ Revised on: 06/12/2015 \\ Accepted on: 14/12/2015 \\ Available online: 19/12/2015}

Key words:

HSPs, seasonal variation, thermal stress, 2D gel

electrophoresis, cyprinid

\begin{abstract}
Barilius bendelisis, one of the principal hill stream fish routinely experiences up to $5-6^{\circ} \mathrm{C}$ of diurnal and $18-20^{\circ} \mathrm{C}$ of annual habitat temperature variations. The role of molecular chaperones like HSPs in enabling adjustment to these two temporally distinct patterns of thermal stress is still less explored. 2-D Gel Electrophoretic brain profile of different laboratory acclimatized populations according to seasonal and daily temperature variations, showed induction of different classes of Heat Shock proteins with different endogenous levels and variation in onset temperatures as well. Low molecular weight HSPs appear to play an important role in fluctuating temperatures while the larger weight chaperones (HSP70, 90) in chronic high temperatures. Further, individuals acclimatized to Summer-like temperature exhibited higher endogenous levels of HSPs as compared to winter-acclimatized individuals. The HSP induction temperature in winter-acclimatized fishes was around $20^{\circ} \mathrm{C}$ whereas the first appearance of HSPs in summer caught as well as 'winter caught-summer acclimatized' individuals was $30-32^{\circ} \mathrm{C}$; an overall shift of $10-12^{\circ} \mathrm{C}$ that could well occur on a seasonal basis. These findings provide first molecular insight into survival strategy of a major hill stream teleost, Barilius bendelisis and suggest that variation in constitutive expression of HSPs plays significant role in imparting tolerance against thermal stress.
\end{abstract}

\section{INTRODUCTION}

Temperature is an important limiting factor at every level of biological organization, influencing cellular processes to organism distribution. In cold stenotherms like fishes, apart from growth and metabolism, water temperature also influences habitat selection and distribution in an ecosystem [1]. As the role of temperature in determining different aspects of fish ecology is quite compelling, thermal variations that occur throughout the life span of an organism be it diurnally or seasonally, alters gene expression which in turn imparts evolutionary adaptations and helps in defining thermal optima and limits for physiological functions. Most of the studies carried out in recent years have focused on quantifying responses to heat and cold shock over a narrow range of high or low temperatures above optima that

\footnotetext{
* Corresponding Author

Department of Zoology \& Biotechnology, Chauras Campus, HNB Garhwal University, PO-Kilkileshwar, Kirtinagar-249161, Uttarakhand. email: saurabhdewan86@gmail.com, Phone:+91-9760195974
}

induce a severe cellular stress response [2-3]. However, very few studies have dealt with actual diurnal or seasonal thermal variations experienced by the organism over course of days to months in nature. Several mechanisms responsible for sensing changes in abiotic factors in their transduction to the cell have been explored since long [4-6] and the most prime approach to analyse how fluctuation in environmental temperature are transduced to the genome was defining how the heat shock response changes with temperature acclimation and monitoring putative molecular factors like regulation of heat shock proteins (HSPs). Quantification of HSPs has also recently served as an efficient indicator to thermal stress and the determinants of thermal habitat quality for some major Indian carps [7-8].The HSP family comprises of highly conserved cellular proteins functioning as molecular chaperones and have been documented in most of the organisms, including fishes. The three major families viz., HSP90 (85-90kDa), HSP70 $(68-73 \mathrm{kDa})$, and some low molecular weight heat shock proteins $(16-47 \mathrm{kDa})$ are being most extensively explored in model organisms and natural populations [9-10]. In unstressed state, these proteins serve a variety of functions including the repair and degradation of distorted or denatured proteins [10] however only under stressful conditions these proteins exhibit molecular 
chaperoning and help an organism to cope up with any environmental, social or physical stressor by binding to the denatured proteins and reducing the probability of any inappropriate protein interactions. In ecological perspective monitoring the expression of HSPs under stressful conditions can serve as an important marker towards the organism's capability to resist against thermal stress. In wild, most ectotherms experience moderate to large thermal variations on daily basis and must sense and react accordingly to recurrent temperature fluctuations. Similarly, seasonal temperature changes demands for substantial phenotypic modifications which occurs over larger time frames. However, genomic and proteomic variations in response to diurnal and seasonal changes in temperature is yet unexplored in hill stream fishes.

In an attempt to explore how these temporally disparate thermal progressions and subsequent acclimations are mediated by proteomic shifts in expression of some major chaperonins we employed 2-Dimensional gel electrophoresis to profile variations associated with daily and seasonal temperature acclimation in an abundant hill stream teleost fish, Barilius bendelisis. None of the study to our knowledge has been conducted on any of the ectotherms in this region so as to predict variations in major chaperonins like HSPs in actual relation to daily and seasonal fluctuations.

Barilius bendelisis (Hamilton, 1807) commonly known as Indian hill trout of the family Cyprinidae inhabits small, shallow pools often isolated from main streams. It is an abundant upland water fish of South East Asia distributed all over spring fed hill streams and rivers throughout Himalayan region. It has dwelled successfully in shallow lotic and seasonal lentic water bodies where most major carps could not. Major habitats include small river-fed pools, shallow flooded watersheds and seasonal flood plains where the fish routinely experiences up to $5-6^{\circ} \mathrm{C}$ of diurnal and $18-20^{\circ} \mathrm{C}$ of annual habitat temperature variations.

Additional to these daily fluctuations, temperature becomes increasingly hot as dry summers approach and the pools evaporate and dry to an extent. Because of this ability to thrive in such highly variable environment where diurnal and seasonal shifts are extreme, $B$. bendelisis, was selected as an excellent study organism for examining shifts in brain chaperone protein expression. We do not propose that abiotic stress such as temperature directly and solely governs the aquatic community as several factors determine the intensity of thermal stress to an organism on a typical day in aquatic habitats. We however wished to explore and characterize variation in expression of chaperones specifically HSPs associated with two aspects of thermal acclimation that had yet been less studied i.e., to discern long-term acclimation to steady temperatures from more brisk daily responses to temperature change. Moreover, as with respect to temperature there is also an interaction between the time of exposure and intensity, here also an attempt is made to examine plasticity in HSP induction temperature and endogenous HSP concentration in brain of $B$. bendelisis, as a mechanism to restore cellular homeostasis in response to thermally induced damage. Thus, the intention of this article is to illustrate the use of such fluctuating environment and the organisms that live there as a means to explore the biological consequences of living in such a steep gradient of thermal stress.

\section{MATERIAL AND METHODS}

\subsection{Study Model}

Hill stream teleost Barilius bendelisis (14.6 $\pm 0.51 \mathrm{gm})$ were caught from nearby streams located in Pauri district of Uttarakhand, India using cast nets. The live fishes were quickly transported to laboratory in exclusively designed polypropylene square containers fitted with battery operated aerators, to ensure continuous oxygen supply. In laboratory, fishes were kept in kept in a glass aquaria $\left(100 \times 50 \times 50 \mathrm{~cm}^{3}\right)$ with well aerated and dechlorinated water circulation, $6.8 \pm 0.5 \mathrm{mg} / \mathrm{l}$ of dissolved oxygen concentration, $7.6 \pm 0.2 \mathrm{pH}$, daily $12 \mathrm{hr}$ photoperiod. The aquaria were set at different temperature regimes viz. Control with the water temperature of collection site as in parental stream $\left(12^{\circ} \mathrm{C}\right.$ for fish collected in December; $27^{\circ} \mathrm{C}$ for fishes collected in MayJune).

Another group of fishes collected in December were kept at summer like condition i.e., $24^{\circ} \mathrm{C}$ and acclimatized for 4 weeks. Fishes were fed twice daily with commercially available pellets except $48 \mathrm{hr}$ prior to the experiment. No mortality was observed during the acclimation period.

\subsection{Experimental Design}

One set of aquariums each were maintained as controls i.e. $12^{\circ} \mathrm{C}$ for fishes procured in winter, $27^{\circ} \mathrm{C}$ for fish caught during summer and one set for winter caught but summer acclimatized fish at $24^{\circ} \mathrm{C}$. In another set designated as Test- 1 aquariums the temperature was raised from control temperatures gradually over a period of four months.

The fishes collected in winter were exposed to gradual increase as $16^{\circ} \mathrm{C}, 20^{\circ} \mathrm{C}, 24^{\circ} \mathrm{C} \& 28^{\circ} \mathrm{C}$ while the fishes caught in summer as well as $24^{\circ} \mathrm{C}$ acclimatized winter fishes were exposed to temperatures $28^{\circ} \mathrm{C}, 32^{\circ} \mathrm{C}$ and $36^{\circ} \mathrm{C}$. Fish were acclimatized to such gradual increasing thermal regimes over a prolonged period to mimic the seasonal variations.

In an additional set of Test- 2 aquariums, daily cycling temperature regimes was mimicked by increase of $6^{\circ} \mathrm{C}$ from control temperatures over short span of $12 \mathrm{hrs}$ followed by immediate removal, and placement into another aquarium containing well aerated water at the appropriate control temperature. This fluctuating temperature regime was designed to mimic the natural seasonal and diurnal temperature variations experienced by $B$. bendelisis. All individuals were anaesthetized with tricaine methane-sulfonate (MS 222, Merck-Germany, $1 \mathrm{~g} /$, $\mathrm{pH}$ buffered with $4 \mathrm{~g} \mathrm{NaHCO}_{3}$ ) and whole brains were dissected out at the end of every exposure temperature. Following procedures were standardized after Goswami et al. [11], Abbaraju et al. [12], Wang et al. [13] and Wulff et al. [14]. 


\subsection{Protein extraction}

Frozen fish brains were placed in pre-autoclaved microcentrifuge tubes and subsequently homogenized on ice in $0.5 \mathrm{ml}$ of $15 \%$ TCA/Acetone (w/v) homogenization buffer with $20 \mathrm{mM}$ dithiothreitol (DTT). The supernatant was separated by centrifugation at $10000 \mathrm{~g}$ for $10 \mathrm{mins}$ at $4{ }^{\circ} \mathrm{C}$ and the pellet obtained was washed twice with $100 \%$ and $80 \%$ acetone $(\mathrm{v} / \mathrm{v})$. The pellet was recovered again by centrifugation at $12000 \mathrm{~g}$ for $15 \mathrm{~min}$ at $4{ }^{\circ} \mathrm{C}$. Residual acetone was removed in a Speed-Vac for about 5 $\min$.

The pellet then was dissolved in $50 \mu$ l of rehydration buffer ( $8 \mathrm{M}$ urea, 2\% CHAPS, $2.8 \mathrm{mg} / \mathrm{ml}$ DTT, $0.5 \%$ IPG buffer and a trace of bromophenol blue) and centrifuged at $12000 \mathrm{~g}$ for 12 $\min$ at $15^{\circ} \mathrm{C}$. The supernatant collected was analysed by twodimensional gel electrophoresis (2-DE).

\subsection{Two dimensional gel electrophoresis}

Overall 300 microgram of protein sample mixed with $167 \mu$ l of rehydration buffer was loaded on linear 3-10 IPG strips (Bio-Rad, USA). Rehydration of the strips and subsequent isoelectric focusing was conducted on Protean i12 IEF Cell (BioRad, USA).

Rehydration was performed overnight at $20^{\circ} \mathrm{C}$ in rehydration tray with total $200 \mu \mathrm{l}$ of protein sample with rehydration buffer. Isoelectric focusing was performed after rehydration with following protocol: $100 \mathrm{~V}$ Rapid for 0:15 hr, 150 V Rapid for 0:25 hr, $8000 \mathrm{~V}$ Gradual for 2:15 hr, $8000 \mathrm{~V}$ Rapid for 26000 Volt Hr, Hold at $500 \mathrm{~V}$. After successful completion of IEF, each strip was equilibrated twice, first with about $10 \mathrm{ml}$ Equilibration buffer-I containing 50mM Tris ( $\mathrm{pH} 8.8$ ), 6M urea, $30 \%$ glycerol, $2 \%$ SDS, $1 \%$ DTT and trace of bromophenol blue for $10 \mathrm{~min}$ and then in fresh Equilibration buffer-II containing $2.5 \%$ iodoacetamide (replacing DTT) for another $10 \mathrm{~min}$. Finally, for second dimension separation $11 \%$ SDS-PAGE was performed initially at $50 \mathrm{~mA}$ for $30 \mathrm{~min}$, followed by a $5 \mathrm{hr}$ run at $200 \mathrm{~V}$ until bromophenol blue front reached the other end. The gel was subsequently silver stained for protein visualization. Five 2-D gels were run for each sample so the 2-D gel images shown here are representative of the five gel images.

\subsection{Silver staining}

Vorum silver staining protocol from Mortz et al. [15] was followed to obtain improved MS compatibility of the gels. The gels were fixed in Fixing solution (50\% methanol, 12\% glacial acetic acid, $0.05 \%$ formalin) for overnight with gentle agitation.

Then washed thrice in $35 \%$ ethanol for $20 \mathrm{~min}$, after which the gels were sensitized $\left(0.02 \% \quad \mathrm{Na}_{2} \mathrm{~S}_{2} \mathrm{O}_{3}\right)$ for $2 \mathrm{~min}$. Sensitizing solution was then removed by washing twice in double distilled water for $5 \mathrm{~min}$ each time and the gels were then incubated for $20 \mathrm{~min}$ in silver staining solution $\left(0.2 \% \mathrm{AgNO}_{3}\right.$, $0.076 \%$ formalin).

The gels were then again washed twice for $1 \mathrm{~min}$ in double distilled water before developing in $6 \% \mathrm{Na}_{2} \mathrm{CO}_{3}, 0.05 \%$ formalin, $0.0004 \% \quad \mathrm{Na}_{2} \mathrm{~S}_{2} \mathrm{O}_{3}$ until sufficient staining and subsequently stopped using Stop solution (50\% methanol, 12\% glacial acetic acid). Stop solution was changed a couple of times which reduced the size and sharpened the spots. The gels were finally washed twice in double distilled water for $5 \mathrm{~min}$ and were ready for scanning.

\subsection{2-D Gel Image analysis}

Images were obtained on a GS- 800 Gel Imaging Densitometer (Bio-Rad, USA). Analysis of 2-D gels was performed on PD Quest 2-D Analysis Software (Bio-Rad, USA). Five gels for each sample from control and experimental fish brains were superimposed to obtain a well representing image. The automated matching of spots was done by PD Quest based on a number of anchor spots that were manually defined, however manual check was also performed to correct missed alignments. Gaussian fitting was measured as $\mathrm{OD} /\left(0.1 \mathrm{~cm}^{2}\right)$ and the quantity of each spot was calculated during spot detection. In order to avoid non-expression related variations in spot intensity and thus accurately predicting semi-quantitative information across different gels, normalization of spots was done analysing their relative volume (volume percentage).

To ensure normalization and a uniform quantification, the $\mathrm{OD} /\left(0.1 \mathrm{~cm}^{2}\right)$ of each spot was divided by the $\mathrm{OD} /\left(0.1 \mathrm{~cm}^{2}\right)$ of all matched and unsaturated spots (peak intensity was within the linear range of the scanner) in the gel resulting in a value given as ppm. ANOVA (analysis of variance) was employed to analyse significant variation in spot intensities among the control and test fishes.

\section{RESULTS AND DISCUSSION}

\subsection{Water Temperatures}

In order to describe the thermal history of hill stream fish, Barilius bendelisis before collection and subsequent analysis, data was collected using hand held digital thermometers from nearby spring fed Khanda stream, where water temperature varies widely on both daily and monthly timescales.

Water temperature was recorded during mid of every month for three consecutive years, March 2011 to February 2014 (Fig. 1a) so as to determine annual temperature fluctuation while diurnal fluctuations in water temperature (every 2 hrs) was recorded in Summer (May \& June), Monsoon (July \& August) and Winter (December \& January) of year 2013 (Fig. 1b).

The water temperature in winters varied between $10^{\circ} \mathrm{C}$ to $15^{\circ} \mathrm{C}$ during a single day and between $25^{\circ} \mathrm{C}$ to $30^{\circ} \mathrm{C}$ in summer months. Annual temperature in Khanda stream ranged from around $12^{\circ} \mathrm{C}$ in December and January to more than $30^{\circ} \mathrm{C}$ in mid June. Thus, the average daily temperature fluctuations recorded were up to $5-6^{\circ} \mathrm{C}$ and the average annual variation in water temperature was around $18-20^{\circ} \mathrm{C}$. Such a huge fluctuation in the habitat temperature makes this species well suited for studies of acclimatization in the heat shock response. 

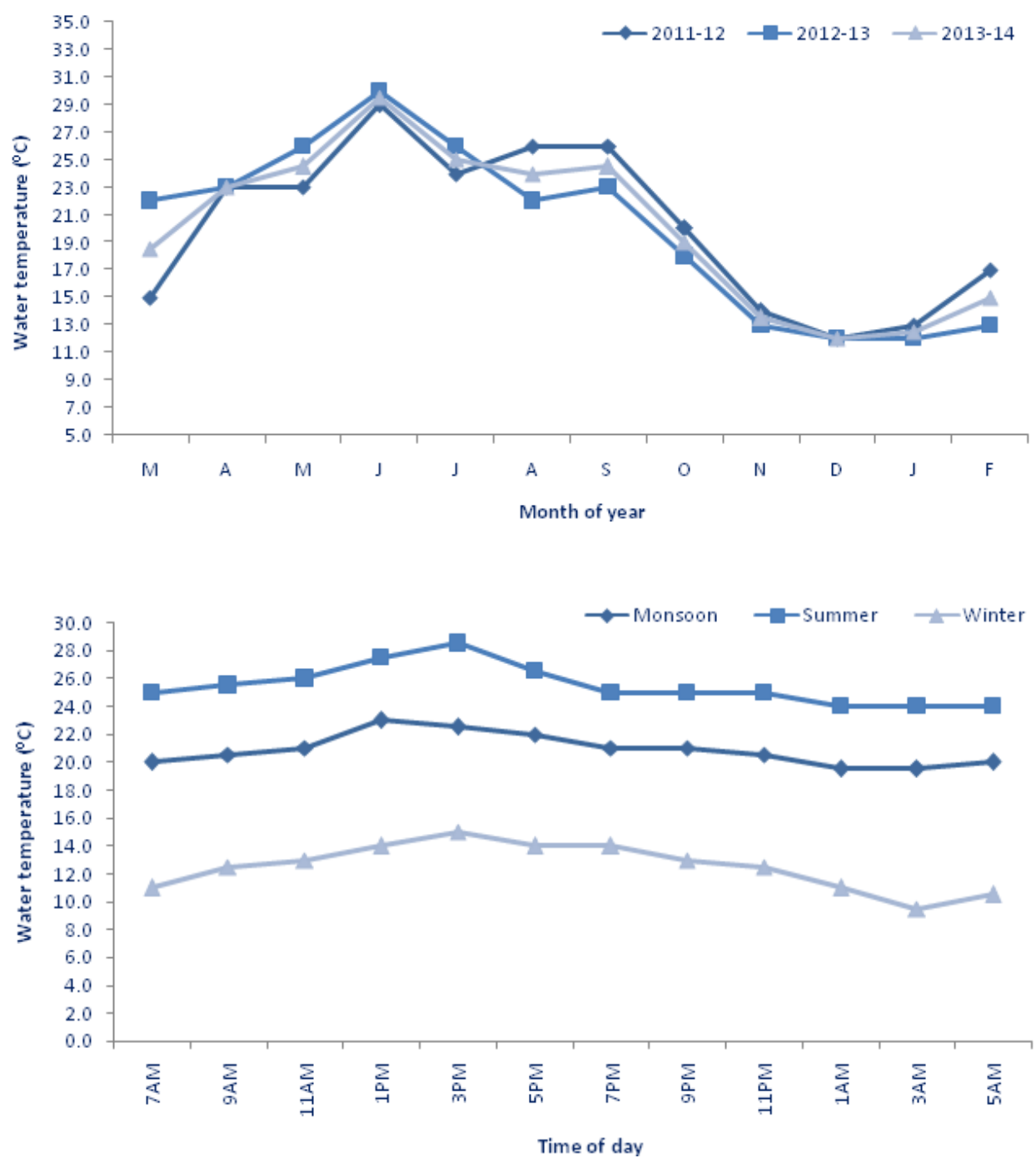

Fig. 1: Water temperature (A) Recorded mid of every month for three consecutive years, March 2011 to February 2014 to determine annual fluctuation, (B) Diurnal fluctuations recorded every 2 hrs in Summer (May \& June), Monsoon (July \& August) and Winter (December \& January) in year 2013.

\subsection{Long $v$ s short-term responses to thermal fluctuations}

Long as well as short-term temperature cycling, strongly induced a number of molecular chaperones (Fig. 2). High molecular weight chaperonins viz., HSP70 and HSP90 were strongly induced during prolonged exposure to constant chronically elevated temperatures. On contrary the smaller heat shock proteins HSP22 and HSP27 were strongly induced (around three to four fold) during the rapid temperature cycling (Fig. 3) where the larger HSPs (70 and 90) were mildly induced (around two fold). This disparity in induction of different class of HSPs indicates a complex response to daily temperature cycling much distinct from gradual exposure to seasonal elevation in temperature. These findings suggest that for $B$. bendelisis chronic daily temperature fluctuations are more 'stressful', i.e. causing more protein damage than constantly varying temperatures over seasonal scales. The conclusion is in congruence with thermal variations in natural habitat where the fish thrives. The apparent significance of the small HSPs in the survival of several fish species in thermally variable habitat has been documented in other studies too [16, 17]. Norris et al. [16] suggested that HSP27 may have a significant role in signal transduction to the cytoskeleton during thermal stress.

Constant temperature acclimation mimicked gradual seasonal changes in daily mean temperature and thus elicited strong variation in expression of high molecular weight HSPs towards preservation of major proteins needed for long term survival or seasonal changes like for reproduction and feeding. On contrary, rapid diurnal fluctuations call for more instant changes in expression of low molecular weight chaperones required for short-term survival or response via transitory mechanism not related to long-term physiological adjustments. Some earlier studies have suggested that acclimations constant thermal environment vs short-term thermal fluctuations apparently result in different physiological phenotypes [18-24]. 

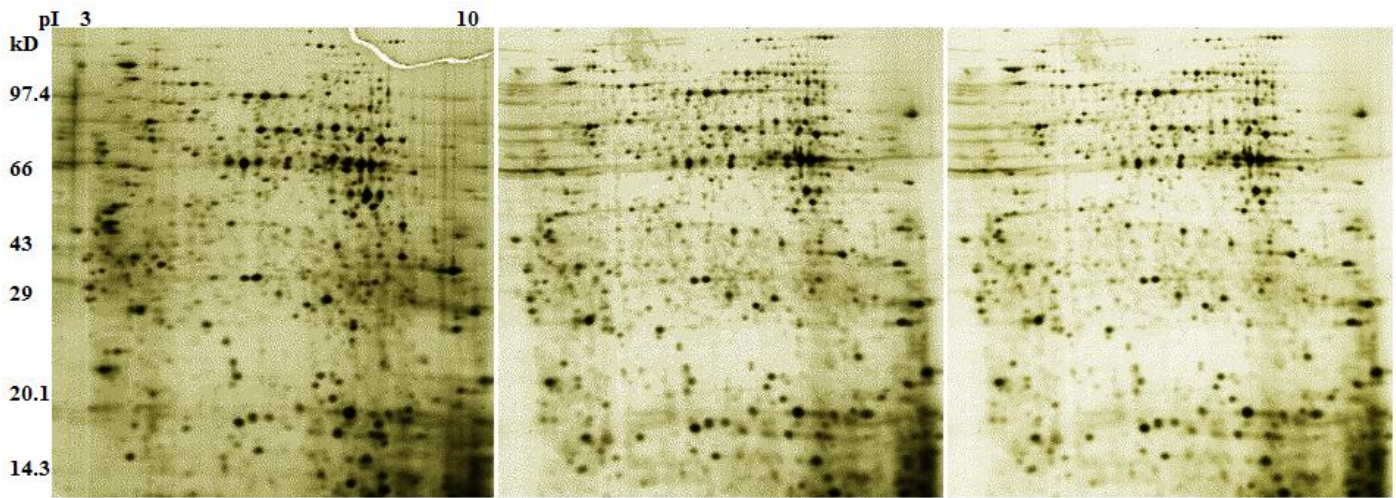

Fig. 2: 2-D gel electrophoretic brain profile of B. bendelisis. (A) Winter caught maintained at $12^{\circ} \mathrm{C},(\mathbf{B}) \mathrm{Winter}$ caught but summer acclimated i.e. at $24^{\circ} \mathrm{C}$ and (C) Summer caught fishes maintained at $27^{\circ} \mathrm{C}$.

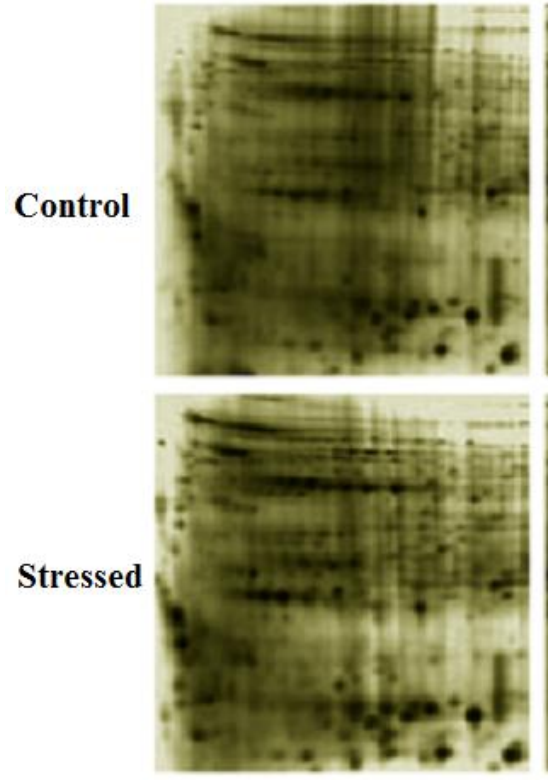

Control $\left(+2^{\circ} \mathrm{C}\right)$
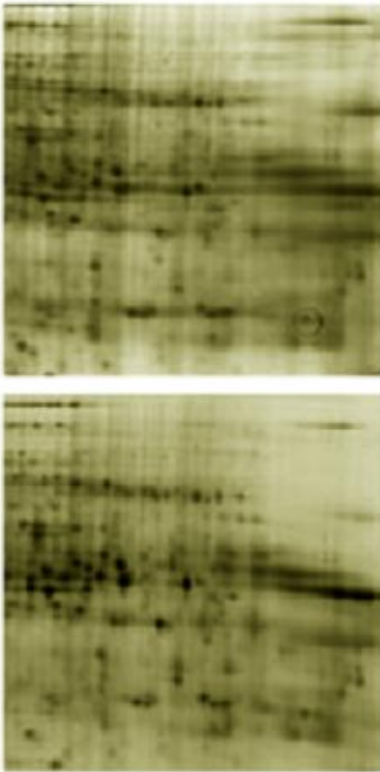

$\left(+4^{\circ} \mathrm{C}\right)$
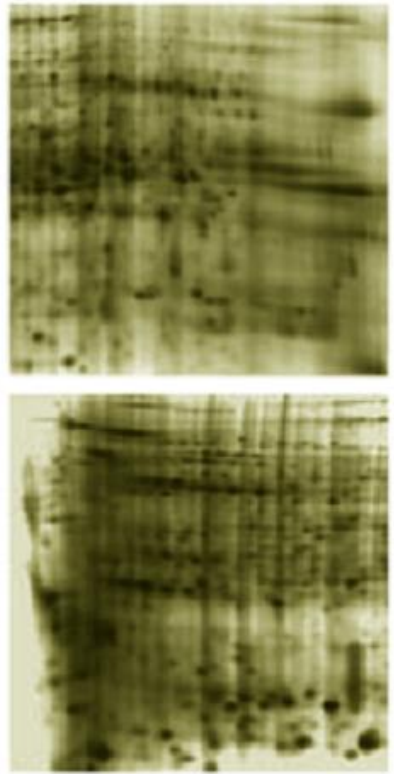

$\left(+6^{\circ} \mathrm{C}\right)$

Fig. 3: Comparative 2-D profile for HSP induction during rapid temperature fluctuations of up to $6^{\circ} \mathrm{C}$ over a span of $12 \mathrm{hrs}$.

In most studies, fluctuating thermal regimes leads to higher thermal tolerance or augmentation in thermal tolerance range as compared to constant conditions that approximated the mean temperature of the fluctuating acclimation. This suggests physiological state of Barilius bendelisis exposed to fluctuating daily temperatures may be much distinct from fish acclimated to gradual seasonal fluctuations.

\subsection{Variation in HSP Induction Temperatures}

HSP expression patterns have been investigated in several species employing two different approaches. In some instances, the HSP expression profiles were assessed in individuals of congeneric species immediately following collection from the field while in another approach the test species is acclimated to the same temperature and then assessed for different parameters of HSP expression. The advantage of acclimation approach is that the thermal exposure is same for all test individuals and thus, HSP expression profile can be studied using a priori assumptions based upon the temperature range of a species. Thus following the latter approach here, we observed a clearly evident temperature-induced change in synthesis of HSPs in brain tissue analysed using twodimensional gel electrophoresis. On a gradual increase of temperature in winter acclimatized fishes, an increasing amount of HSP expression was seen at higher exposure temperatures $16^{\circ} \mathrm{C}$, $20^{\circ} \mathrm{C}, 24^{\circ} \mathrm{C} \& 28^{\circ} \mathrm{C}$. Minimal expression of these proteins occurred in the $12^{\circ} \mathrm{C}$ (control) fish and molecular mass standards indicated that the spots showing the large temperature dependent increase in rate of synthesis was closed to $90 \mathrm{kDa}$, followed by 70 $\mathrm{kDa}$. The HSP induction temperature $\left(\mathrm{T}_{\mathrm{ON}}\right)$ of these winter acclimatized set was observed to be around $20^{\circ} \mathrm{C}$ and the increase in HSP synthesis relative to control $\left(12^{\circ} \mathrm{C}\right)$ fish was significant by $24^{\circ} \mathrm{C}$ (Fig. 4a). Further, we also attempted to resolve whether induction temperature of Heat shock proteins, shifts in response to adaptation to the different temperatures? In $B$. bendelisis caught in winter but acclimatized to $24^{\circ} \mathrm{C}$ for 4 weeks prior to experimentation, the expression data suggests a significant shift in induction temperature $\left(\mathrm{T}_{\mathrm{ON}}\right)$ i.e., higher than that of the winteracclimatized fish. 

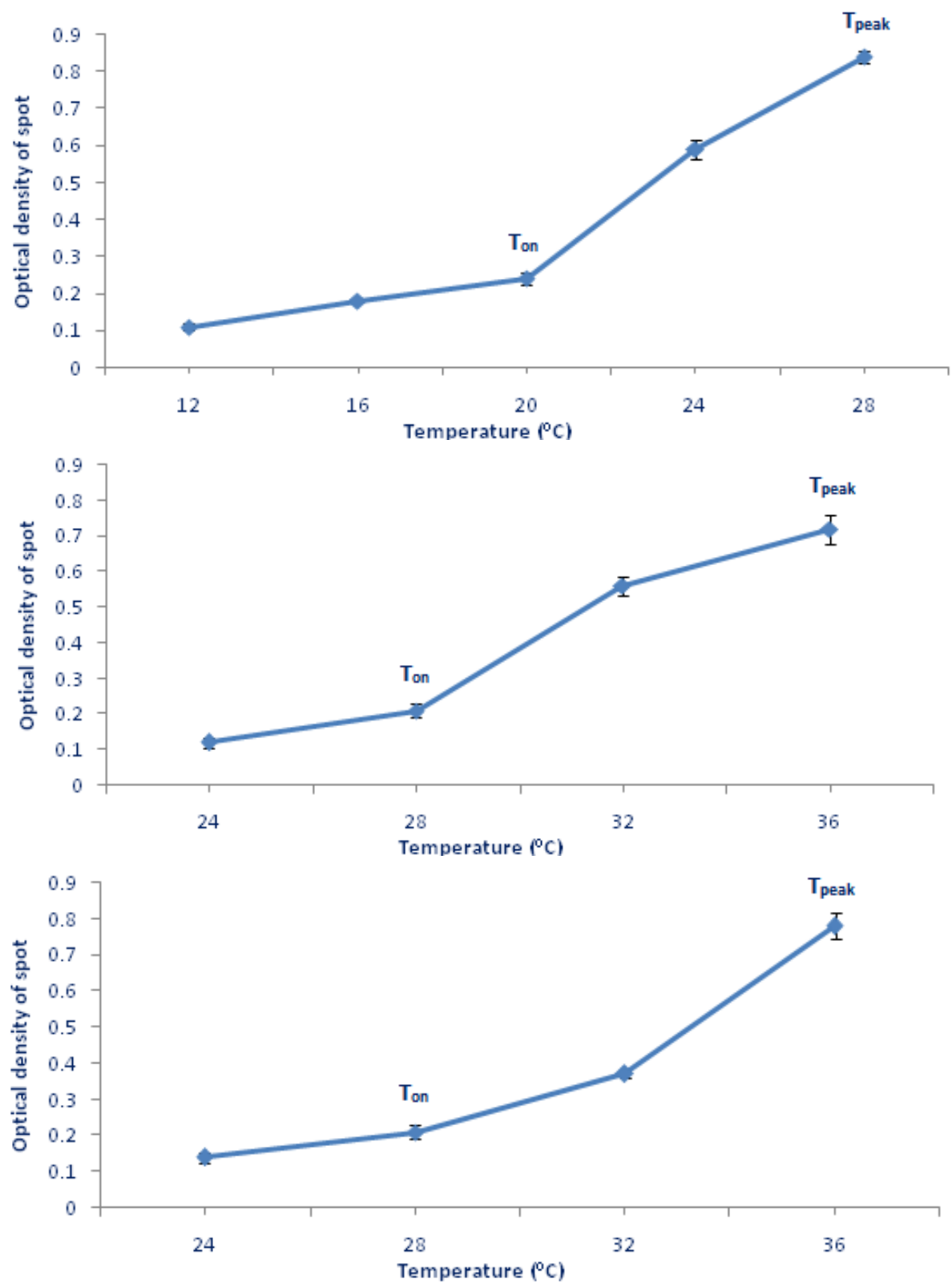

Fig. 4: Onset $\left(\mathrm{T}_{\mathrm{ON}}\right)$ and Peak $\left(\mathrm{T}_{\mathrm{PEAK}}\right)$ temperatures for HSP synthesis (A) Winter acclimatized (B) Winter caught but summer acclimated and (C) Summer acclimatized fishes.

Where a winter-acclimatized fish exhibited an approximate doubling of large molecular weight HSPs by $28^{\circ} \mathrm{C}$, the winter caught but $24^{\circ} \mathrm{C}$ acclimated fish did not show doubling until $32^{\circ} \mathrm{C}$ (Fig. 4b). Similarly, in fishes caught during summer when habitat temperature of $30^{\circ} \mathrm{C}$ existed, the HSP induction temperature was also significantly higher, much like the winter caught $24^{\circ} \mathrm{C}$ acclimated fish (Fig. 4c). In the summer-acclimatized fishes, no significant increase in synthesis of these HSPs was found at exposure temperatures below $32^{\circ} \mathrm{C}$.

\subsection{Variation in HSP Synthesis}

Regardless of the importance that has been given to the research on HSPs, workers have rarely addressed the effects of natural thermal variations on the synthesis and intracellular levels of Heat shock proteins. In this study, the threshold induction temperature for HSPs showed seasonal differences, rising to higher temperatures in both summer caught and 'winter caught but summer acclimatized fishes (Fig. 5). The threshold induction temperature was determined as that temperature at which HSP synthesis was first apparent. In winter-collected fishes the induction temperature was around $20^{\circ} \mathrm{C}$; however, the first appearance of HSPs in the summer caught as well as 'winter caught-summer acclimatized' individuals showed shifts to 30 $32^{\circ} \mathrm{C}$. Overall, there was a change of $10-12^{\circ} \mathrm{C}$ in induction temperatures that could well occur on a seasonal basis. It is quite conclusive that the individuals turn on HSP genes at a "later" point following heat stress. This shift in the induction temperature well reflects seasonal acclimatization and a kind of thermal hardening 
which could be a result of repeated bouts of exposure to thermal stress during extreme summers. The detailed mechanism for such plasticity in the induction temperature for HSP genes on a seasonal basis is yet being explored. However, it is quite evident that the set-point at which HSP genes are activated and the corresponding cellular HSP levels keep track of each other, as warm acclimated fishes showed higher threshold induction temperatures and higher endogenous concentrations of HSPs.
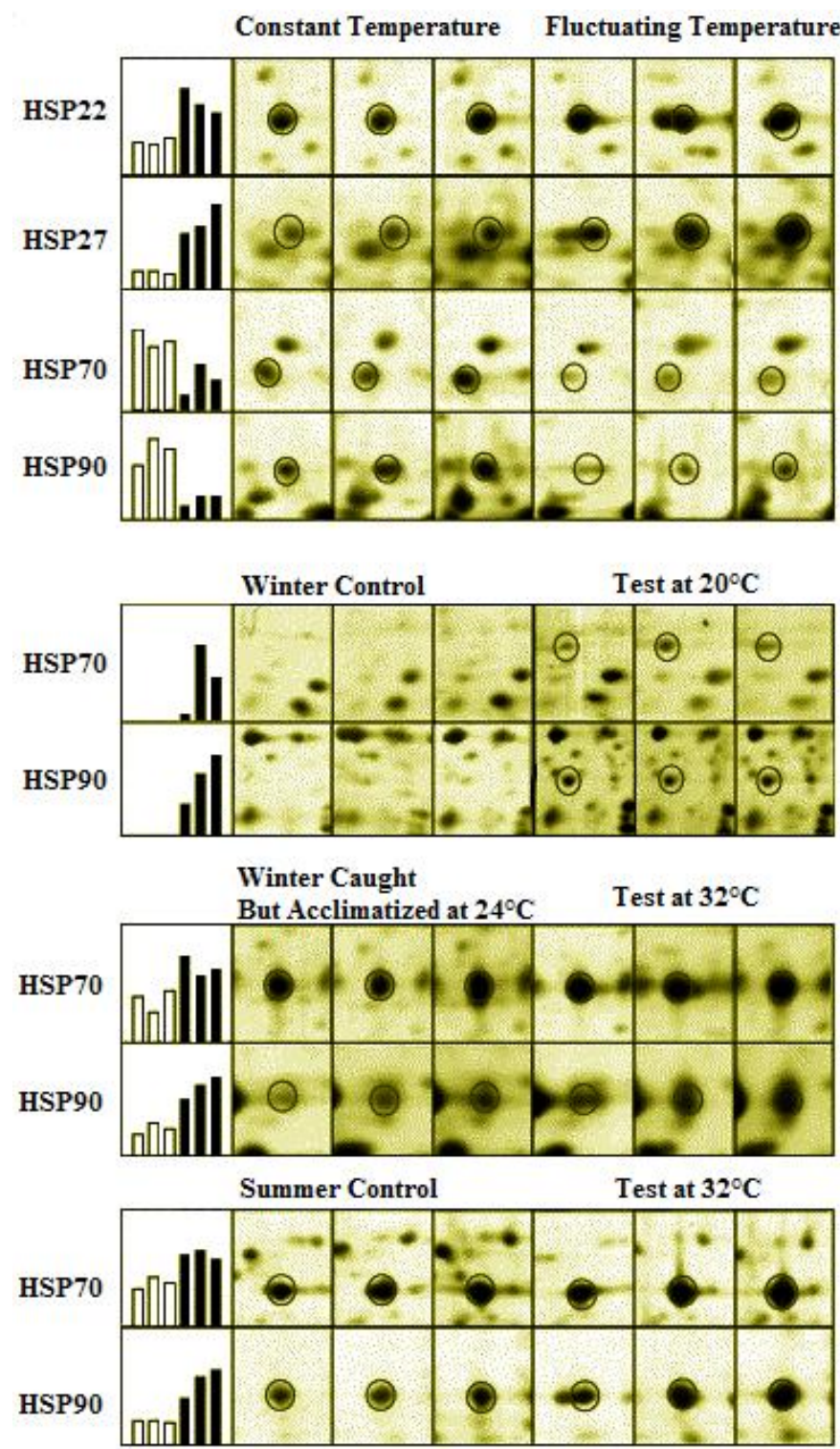

Fig. 5: Overall variation in HSP synthesis in response to constant and fluctuating thermal regimes as well as in different acclimated population of $B$. bendelisis.

As proposed under, the 'Cellular thermometer model' high concentration of HSPs effectively deal with denatured proteins until a threshold is achieved where these chaperones complex with HSF1 are recruited, HSF1 is released and HSP genes are activated [25]. This development efficiently explains how the induction temperature varies in ectotherms on both diurnal and seasonal basis. As these chaperones have an expected half-life of several days and hence the consequence of synthesizing additional HSPs can be lasting and cumulative. The combination of repeated bouts of heat stress and subsequent activation of inducible HSP genes can to an extent explain the induced seasonal thermo tolerance. As per our knowledge, this study provide the first molecular insight into seasonal variation in synthesis of a specific type of chaperone proteins like HSPs which play a significant role in imparting tolerance to hill stream teleost, Barilius bendelisis against varying thermal stress.

Overall, these findings demonstrates that HSP induction event and the intensity of expression is a composite of both the magnitude and the duration of thermal stress experienced by an organism both diurnally and seasonally. The regulation of HSF1 activation and subsequent initiation of HSP gene expression in response to the intensity of stress has been proposed as an important survival mechanism for ectotherms in fluctuating or unpredictable thermal environments. The seasonal variation in HSP70, HSP90 and HSF1 levels on the temperature sensitivity of HSF1 activation has important implications in plasticity of HSP induction temperature commonly observed in these organisms. In context of the 'cellular thermometer model' there exists dynamic tension between the ability of different HSPs to repress HSF1 activation and their function as molecular chaperones for moderately denatured proteins. This regulation in organisms like ectotherms is also influenced by the fact that there is marked seasonality in the endogenous concentrations of HSP present in a tissue, as well as in the threshold induction temperature for different HSPs [2]. In warmer months, the endogenous levels of HSP and the temperature at which they become inducible are both comparatively higher than in the colder months [26-30]. Their relatively higher levels inhibit early onset of HSP expression and thus leads to a higher $\mathrm{T}_{\mathrm{ON}}$, with constant levels of HSF1. Increased concentration of HSF1, however allows earlier onset of the response as free HSF1 monomers form active trimers at lower temperatures, assuming that levels of HSPs and other protein stabilizing molecules like compatible osmolytes, stay equal. Our results have implications for the role that HSPs play as elements in environmental adaptation processes in ectotherms and further, provide evidence in support of one of the proposed mechanisms for regulating transcription of HSP encoding genes. From the perspective of environmental adaptation, this study indicate that the heat shock response play elemental role in environmental adaptation processes in this hill stream fish and indicate that the heat shock response is not genetically stringent but is a variable in response to surrounding fluctuations.

\section{CONCLUSION}

Different studies have established that organisms in nature exhibit diverse patterns of HSP expression like expressing different isoforms related to particular HSP family, variation in endogenous levels and the onset temperature at which HSP genes are activated. The ultimate consequences of these variations and significance of the plasticity in HSP expression to the organism in 
nature is yet much debated. Further, the evolution of the plasticity in heat shock response or variation in the expression of HSP genes with changes in environmental temperature are critically unexplored in terms of ecological physiology of the thermal stress. As reviewed by Feder and Hofmann [2], most studies on species with wide thermal niches though have documented differential heat-shock response but have not explored how these variations relate to the actual temperatures that these species experience in wild. Chaperone protein expression data presented in this study derives a broader conclusion that constant and fluctuating thermal regimes elicit different transcriptional response and thus are likely to mediate different physiological processes.

The varied responses observed during acclimation to constant and fluctuating temperatures discussed here may also have broader proposition in aquatic biology studies on other species inhabiting fluctuating environments. Like, many aquatic organisms migrate to relatively stable thermal environment during some part of their life cycle like reproductive phase. Most studies on thermal biology of such species are based on acclimation to constant temperatures; however a much different perspective could be obtained from observation on daily fluctuations in such habitats. The difference in proteomic responses in constant vs fluctuating temperatures indicate variation in physiological responses to diurnal vs seasonal changes in temperature. While there may be daily temperature fluctuations in all seasons, the mean temperature level is likely to change, along with the amplitude of fluctuation. The physiological literature presents numerous records of how functional processes are altered in response to thermal stress like variation in enzyme concentrations, physical characteristics of membranes and even the phenotypic plasticity of thermal acclimation has also been addressed. Most studies on HSP expression have focused on either linking the temperature of HSP production to thermal habitat, correlation of HSP levels with thermal tolerance or have attempted to draw inferences about the recent stress exposure on some organism or population. These studies have found preference in some ectotherms like fishes because of their ability to resist abiotic stress and its implications in better understanding of the ecophysiology of the species. However, studies on the same organisms relating to the temperature thresholds and activation of regulatory steps like HSF1 which primarily transduce the stress stimulus to the gene before synthesis of heat shock proteins are still rare. This study provides correlation between optimum temperature and HSP induction temperature with a clue that the regulation of HSP expression in different species has different threshold points for its induction which are not genetically stringent but are subject to the seasonal or diurnal acclimation especially for organisms which encounter a wide range of temperature fluctuations.

\section{ACKNOWLEDGEMENT}

We greatly acknowledge Department of Science and Technology, Government of India for providing INSPIRE fellowship to Saurabh Dewan and Head, Department of Zoology \& Biotechnology, HNB Garhwal University for providing the necessary research facilities.

\section{REFERENCES}

1. Torgersen CE, Price DM, Li HW, McIntosh BA. Multiscale thermal refuge and stream habitat associations of Chinook salmon in Northeastern Oregon. Ecological Applications. 1999; 9:301-319.

2. Feder ME, Hofmann GE. Heat-shock proteins, molecular chaperones, and the stress response: evolutionary and ecological physiology. Annual Review of Physiology. 1999; 61:243-282.

3. Fujita J. Cold shock response in mammalian cells. Journal of Molecular Microbiology and Biotechnology. 1999; 1:243-255.

4. Morimoto RI, Jurivish DA, Kroeger PE, Mathur SK, Murphy SP, Nakai A, Sarge K, Abravaya K, Sistonen LT. Regulation of heat shock gene transcription by a family of heat shock factors. In: Morimoto RI, Tissieres A, Georgopoulos C, editors. The biology of heat shock proteins and molecular chaperones, New York: Cold Spring Harbor Laboratory Press; 1994, p. 417-455.

5. Kiiltz D, Burg M. Evolution of osmotic stress signalling via MAP kinase cascades. Journal of Experimental Biology. 1998; 201:30153021.

6. Owen ME, Hofmann GE. Resetting the thermostat: Changes in HSP induction temperatures in Mytilus trossulus. American Zoologist. 1998; 38:48A.

7. Purohit GK, Mahanty A, Suar M, Sharma AP, Mohanty BP, Mohanty S. Investigating hsp Gene Expression in Liver of Channa striatus under Heat Stress for Understanding the Upper Thermal Acclimation. BioMed Research International. 2014 June 9; 381719.doi: org/10.1155/2014/381719.

8. Mohanty BP, Bhattacharjee S, Mondal K, Das MK. HSP70 expression profiles in white muscles of riverine catfish Rita rita show promise as biomarker for pollution monitoring in tropical rivers. National Academy Science Letters. 2010; 33(5\&6):177-182.

9. Basu N, Todgham AE, Ackerman PA, Bibeau MR, Nakano K, Schulte PM, Iwama GK. Heat shock protein genes and their functional significance in fish. Gene. 2002; 295:173-183.

10. Sorensen J, Loeschcke V. Decreased heat-shock resistance and down-regulation of HSP70 expression with increasing age in adult Drosophila melanagaster. Functional Ecology. 2002; 16:379-384.

11. Goswami M, Hariprasad G, Dubey A, Kumar R, Nagpure NS, Srinivasan A, Singh TP, Lakra WS. Proteomics Analysis of Liver Tissue of Labeo rohita. Current Proteomics. 2015; 12:56-62.

12. Abbaraju NV, Boutaghou MN, Townley IK, Zhang Q, Wang G, Cole RB, Rees BB. Analysis of Tissue Proteomes of the Gulf Killifish, Fundulus grandis by 2D Electrophoresis and MALDI-TOF/TOF Mass Spectrometry. Integrative and Comparative Biology. 2012; 52:626-635.

13. Wang M, Chan LL, Si M, Hong H and Wang D. Proteomic analysis of hepatic tissue of zebrafish (Danio rerio) experimentally exposed to chronic microcystin-LR. Toxicological Science. 2009; 113(1):6069.

14. Wulff $\mathrm{T}$. Long term anoxia in rainbow trout investigated by 2-DE and MS/MS. Proteomics. 2008; 8:1009-1018.

15. Mortz E, Krogh TN, Vorum H, Görg A. Improved silver staining protocols for high sensitivity protein identification using matrixassisted laser desorption/ionization-time of flight analysis. Proteomics. 2001; 1:1359-1363.

16. Norris CE, Brown MA, Hickey E, Weber LA, Hightower LE. Lowmolecular-weight heat shock proteins in a desert fish (Poeciliopsis lucida): Homologs of human HSP27 and Xenopus HSP30. Molecular Biology and Evolution. 1997; 14:1050-1061.

17. Hightower LE, Norris CE, Di Iorio PJ, Fielding E. Heat shock responses of closely related species of tropical and desert fish. American Zoologist. 1999; 39:877-888. 
18. Lowe $\mathrm{CH}$, Heath WG. Behavioral and physiological responses to temperature in the desert pupfish Cyprinodon macularius. Physiological Zoology. 1969; 42:53-59.

19. Feldmeth CR, Stone EA, Brown JH. An increased scope for thermal tolerance upon acclimating pupfish (Cyprinodon) to cycling temperatures. Journal of Comparative Physiology. 1974; 89:39-44.

20. Otto RG. The effects of acclimation to cyclic thermal regimes on heat tolerance of the western mosquito fish. Transactions of American Fisheries Society. 1974; 331-335.

21. Shrode JB, Gerking SD. Effects of constant and fluctuating temperatures on reproductive performance of a desert pupfish, Cyprinodon nevadensis nevadensis. Physiological Zoology. 1977; 50:1-10.

22. Woiwode JG, Adelman IR. Effects of starvation, oscillating temperatures, and photoperiod on the critical thermal maximum of hybrid striped $\mathrm{x}$ white bass. Journal of Thermal Biology. 1992; 17:271-275.

23. Heath AG, Turner BJ, Davis WP. Temperature preferences and tolerances of three fish species inhabiting hyperthermal ponds on mangrove islands. Hydrobiologia. 1993; 259:47-55.

24. Podrabsky JE, Somero GN. Changes in gene expression associated with acclimation to constant temperatures and fluctuating daily temperatures in an annual killifish Austrofundulus limnaeus, The Journal of Experimental Biology. 2004; 207:2237-2254.

25. Craig EA, Gross LA. Is HSP70 the cellular thermometer? Trends in Biochemical Sciences. 1991; 16:135-140.

26. Dietz TJ, Somero GN. The threshold induction temperature of the 90$\mathrm{kDa}$ heat shock protein is subject to acclimatization in eurythermal goby fishes (Genus Gillichthys). Proceedings of National Academy of Science USA. 1992; 89:3389-3393.
27. Fader SC, Yu Z, Spotila JR. Seasonal variation in heat shock proteins (HSP70) in stream fish under natural conditions. Journal of Thermal Biology. 1994; 19:335-341.

28. Hofmann GE, Somero GN. Evidence for protein damage at environmental temperatures: Seasonal changes in levels of ubiquitin conjugates and HSP70 in the intertidal mussel, Mytilus trossulus. Journal of Experimental Biology. 1995; 198:1509-1518.

29. Roberts DA, Hofmann GE, Somero GN. Heat-shock protein expression in Mytilus californianus: Acclimatization (seasonal and tidal height comparisons) and acclimation effects. The Biological Bulletin. 1997; 192:309-320.

30. Buckley BA, Owen ME, Hofmann GE. Adjusting the thermostat: the threshold induction temperature for the heat-shock response in intertidal mussels (Genus Mytilus) changes as a function of thermal history. Journal of Experimental Biology. 2001; 204:3571-3579.

\section{How to cite this article:}

Dewan S, Singh Y and Bhatt JP. Insight into interplay of some molecular chaperones in a hill stream teleost, Barilius bendelisis under wide seasonal and diurnal thermal fluctuations. J App Biol Biotech, 2015; 3 (06): 034-042. DOI: 10.7324/JABB.2015.3606 